\title{
EDITORIAL
}

\section{(Re-)Introduction to the journal}

\author{
MatthewJohnson,m.johnson@lancaster.ac.uk \\ Lancaster University, UK
}

To cite this article: Johnson M. (2019) (Re-)Introduction to the journal, Global Discourse, vol 9, no 1, 3-4, DOI: 10.1332/204378918X15453934505888

It is with great pleasure that I introduce the first issue of Global Discourse as published by Bristol University Press (BUP). This new, long-term publishing arrangement promises to secure the journal's future, to protect our commitment to working with young, engaged guest editors to examine issues as they emerge and to ensure that we realise our commitment to innovation through formal deployment of new sections that we have sought to develop since the journal's inception. The fact that BUP is not for profit has a natural synergy with the background and vision of the journal and is already enabling us to realise some of our longstanding ambitions.

From this volume onwards, we will supplement our discursive model, in which articles are published with accompanying replies and in which book reviews are conducted in symposia with replies from authors, with a formal Policy section featuring three pieces by policy makers on a key element of each issue. These policy pieces fulfil our original ambition to engage with non-academic audiences in order to apply the ideas examined within the academic content of the journal. In an era of increased concern for impact and engagement, this is a tangible means of demonstrating the relevance and importance of materials that are often, unfairly, regarded as irrelevant to practice.

Beyond our Policy pieces, we are reintroducing a Social Media section that disappeared with our first publishing contract in 2013 (Johnson, 2013). These sections are not simply a means of making material accessible and definitely not an attempt to subtract academic rigour from publishing. Rather, our Policy section will serve as a forum for thoroughgoing debate and development of approaches, with discussions continuing across and between journal issues. In addition to publishing pieces by guest editors and key contributors to each issue, our Global Discourse Blog will host themed sections that transcend issues and enable early career researchers, in particular, to hone their work prior to submission of peer-reviewed research. The Blog is intended to be provocative and to leave room for experimentation, but will be subject to a substantive review process.

In terms of content, we will continue to work with outstanding scholars on issues of global importance as they emerge. We have sought, in shaping the publishing schedule, 
to identify those issues that will only increase in importance as our relationship with BUP develops, believing that the ties forged with policy makers will ensure that contributors see the impact of their work borne out in practice. This is illustrated by the first issue, The Limits of EUrope, which is edited by Jan Grzymski, Lazarski University, and Russell Foster, King's College London. It exemplifies the ethos of genuinely discursive publishing in applied research that we sought to advance upon the journal's founding a decade ago, but exceeds in quality and depth of contributions any expectations that we held at that time (Johnson, 2008). We will endeavour to ensure that future issues follow in this light, containing ground-breaking contributions from a range of, often mutually contradictory, positions that reflect our editorial commitment to non-ideological publishing.

This will only be possible as a consequence of the work, over many years, by contributors too numerous to list in full. Here, I shall simply say that I will always remain grateful to Mark Edward, for his patience, insight and vision; Simon Mabon, Rosie Mutton, Russell Foster and Gareth Bowden for their editorial work; Patrick Bishop for providing support as our Head of Department at Lancaster University; Ronaldo Munck, for his ever generous and incisive contributions; Stuart Sim, for his guidance and diligence; the large number of anonymous reviewers who supported our BUP proposal; and, in particular, Julia Mortimer, Edwina Thorn, Heather Gibson and Jessica Miles from BUP, who are a credit to BUP and the University of Bristol. I am indebted to you all deeply and sincerely.

\section{References}

Johnson, M.T. (2008) 'Editorial Introduction', Global Discourse, 1(1): 1-4, :https:// doi.org/10.1080/23269995.2010.10707832

Johnson, M.T. (2013) 'Introduction to the journal', Global Discourse, 3(1): 1-2, https://doi.org/10.1080/23269995.2013.804699 